\title{
Women, productivity and progress
}

\begin{abstract}
The challenge for Africa is to ensure that the gender imbalance in the practising of science, technology and innovation [STI] is addressed. None of us here underestimates the importance of science, technology and innovation for socio-economic development, in both the developed and developing world. The involvement of women in STI activities is thus crucial for contributing to the development of nations.
\end{abstract}

Minister Naledi Pandor, $2015^{1}$

In the 114 years over which Nobel Prizes have been awarded in six categories, 47 women have received the award, of whom just 16 have been in what might be called the 'disciplinary' areas of the awards (i.e. not including Literature and Peace). Two of these prizes were in Physics, five in Chemistry, eight in Physiology and Medicine, and just one in Economics.

In the 70 years during which Fields Medals have been awarded, only one woman has been a winner: Maryam Mirzakhani, in 2014. The Abel Prize (2003-2015) has never been won by a woman. And the Holberg Prize (2004-2015) has been awarded 14 times, but to women on just three occasions. It would be remiss if we were not also to mention that just 3 of the 13 members of the Council of the Academy of Science of South Africa (ASSAf) are women (although a woman leads the Academy internally as Executive Officer); and that the University of Cape Town has only just this year appointed its first ever woman Dean of Engineering and the Built Environment (Professor Alison Lewis, a Chemical Engineer) in the 186-year history of the institution.

Perhaps, however, one of the most deplorable cases of the marginalisation of women scholars is that of Amalie Noether (born in 1882) whose first great theorem demonstrates that 'symmetries give rise to conservation laws'. This insight has been the foundation for almost every fundamental discovery in Physics since then. Yet despite being recognised as a genius, and having a professor for a father, she was denied entry to a university on the basis of her gender. After a struggle, she was allowed to study and received a PhD, but was unable, as a woman, to find a university position. She was finally recognised as one of the world's leading experts in the mathematics of symmetry - without ever having had an appointment, a salary or a title.

It is probable that these rather gloomy conditions may be attributed to at least four fundamental causes. In many parts of the world, historically, girls and women have not had the same access to education as their male counterparts have enjoyed. There is a lingering tradition, in some schools, of encouraging boys to study physical science and girls to focus on biology and to become teachers while methods of teaching science have not been mainstreamed appropriately to consider gender equality in, for example, teacher education and curriculum development. Institutional structures, and a persistent lack of support in the workplace, have disadvantaged women in their quest to progress in scientific careers. And, finally, there has been, and remains, deliberate and persistent, although often hidden, discrimination in academia as elsewhere in society. A recent review of an article submitted to PLOS One, suggesting that the women authors find a man to work with if they wanted an acceptable paper, is just one example of blatant sexism. ${ }^{2}$

Yet the fact that women have won at least some of the world's most prestigious scientific prizes, and continue to play leading roles across the full range of scientific research, serves to remind us that the distribution of intelligence, research skills and imagination is not genderbased, any more than it is ethnicity-based, but fundamental to the human condition. For example, who, in South Africa and elsewhere, is not aware of the critical roles played in the identification of the coelacanth and its introduction to the world of science, by Marjorie Courtenay-Latimer and Margaret Smith?

Ms Pandor's urging has both moral and practical force. Moral, because there is absolutely no justifiable reason for the exclusion of over half the population of a country or continent - or the world, in fact. And practical because, like the rest of the world, Africa needs all the research and applied skills that can possibly be mustered across the complete spectrum of disciplines. The entire population needs equal access to education, training and employment.

It remains true, however, that women still are the minority members of science and engineering disciplines in academia. The Association of African Women in Science and Engineering estimates that women constitute no more than $20 \%$ of the academics in these fields in Africa $^{3}$, although even in the USA, the number reflects a minority: $46 \%$ of academics in science and engineering fields are women (the number is bolstered by the $16 \%$ in Life Sciences) ${ }^{4}$. In this regard, GenderlnSITE (Gender in Science, Innovation, Technology and Engineering) southern Africa - implemented by ASSAf - seeks to: demonstrate how gender analysis of science and technology can lead to improved development in key development sectors; highlight women's transformative role in development and the contributions of women to SITE, and how science and technology can support women and men; and promote leadership of women in SITE.

WISE - the South African Association of Women in Science and Engineering - offers this apt observation:
Africa, including South Africa, has a critical shortage of trained technological people. ....Increasing the number of technologically trained people, both men and women, is essential for development.

The same is not only true for the academic world - the realms of teaching and research. Catalyst ${ }^{\odot}$, a non-profit organisation whose mission is to expand opportunities for women and business, has gathered research findings from a number of respectable sources. Their collected research shows that

women board directors make invaluable contributions to companies and the boards on which they serve. But the benefits of having women on the board go beyond simply influencing board deliberations, better meeting attendance and preparation, and improved boardroom behavior. In fact, having more women on the board may help companies solve the problem of insufficient numbers of women in their executive ranks. ${ }^{6}$

They go on to say that
Fortune 500 companies with the highest representation of women board directors attained significantly higher financial performance, on average, than those with the lowest representation of women board directors. ${ }^{7}$

In any sphere of the intellectual, public and private endeavours that manage critical physical and non-physical resources, and that contribute to their creation and effective use, it is people who are critical. But the Catalys ${ }^{\odot}$ research foregrounds the important finding that the dominance of men does not just limit the 'pool of skills' but also limits productivity - and creative, sound decision-making.

Various arguments around shifting the balance of ethnicity of staff in universities and other research institutions refer to the time it takes for black scholars to reach the levels of experience required for professorships. True or not, this case cannot be applied in women's 
circumstances. South Africa, at least, has a host of distinguished women scholars who, like Alison Lewis, are admirably suited to lead Departments, Faculties, Universities, Research Foundations and Institutes. This Journal supports their right to be fully recognised for the research, teaching and management leaders that they are - and to be appointed accordingly. Three of South Africa's seven world-leading researchers in their fields, as determined in 2014, are women.

There can be no more excuses.

\section{References}

1. Minister Naledi Pandor on women scientists [press release on the Internet]. c2015 [cited 2015 May 05]. Available from: http://www.gov.za/ speeches/minister-naledi-pandor-women-scientists-28-apr-2015-0000

2. Cochran A. Sexism in peer review [homepage on the Internet]. c2015 [cited 2015 May 08]. Available from: http://scholarlykitchen.sspnet. org/2015/05/07/sexism-in-peer-review/?utm_source $=$ feedburner\&utm medium $=$ email\&utm campaign $=$ Feed\%3A+ScholarlyKitchen $+\% 28$ The +Scholarly+Kitchen $\overline{\%} 29$

3. African Women in Science and Engineering [homepage on the Internet]. No date [cited 2015 May 08]. Available from: http://www.aawse.org/

4. National Science Board. Science and engineering indicators 2014 Arlington, VA: National Science Foundation; 2014. Available from: http:// www.nsf.gov/statistics/seind14/content/chapter-5/at05-15.pdf

5. The Association of South African Women in Science and Engineering [homepage on the Internet]. No date [cited 2015 May 05]. Available from: http://web.uct.ac.za/org/sawise/

6. First step: Gender diversity at the top pays off [document on the Internet]. c2014 [cited 2015 May 05]. Available from: http://catalyst.org/system/files/ first_step_gender_diversity_at_the_top_0.pdf

7. Companies with more women board directors experience higher financial performance, according to latest Catalyst bottom line report [homepage on the Internet]. No date [cited 2015 May 05]. Available from: http://www. catalyst.org/media/companies-more-women-board-directors-experiencehigher-financial-performance-according-latest 